\title{
PROLONGED DISCORDANT XENOGRAFT SURVIVAL AND DELAYED XENOGRAFT REJECTION IN A PIG-TO-BABOON ORTHOTOPIC CARDIAC XENOGRAFT MODEL
}

$\mathrm{He} \mathrm{Xu}, \mathrm{MD}^{\mathrm{a}}$

Steven R. Gundry, MDa

Wayne W. Hancock, MD ${ }^{\mathrm{b}}$

Goro Matsumiya, $\mathrm{MD}^{\mathrm{a}}$

Craig W. Zuppan, $\mathrm{MD}^{\mathrm{c}}$

Toro Morimoto, $\mathrm{MD}^{\mathrm{a}}$

James Slater, $\mathrm{MD}^{\mathrm{d}}$

Leonard L. Bailey, MD
Objective: Our objectives were to study delayed xenograft rejection and the effectiveness of pretransplantation total lymphoid irradiation combined with immunosuppression on rejection in a pig-to-baboon cardiac xenograft model. Methods: Baboons were treated with pretransplantation total lymphoid irradiation, cyclosporine A (INN: ciclosporin), and methotrexate. Orthotopic pig-to-baboon cardiac transplantations were performed after depletion of circulating xenoreactive natural antibody by pretransplantation donor organ hemoperfusion. Tissue samples were collected for immunologic and immunopathologic evaluation. Results: Pig cardiac xenografts survived more than 18 and 19 days without evidence of hyperacute rejection. Immunologic analysis of serum samples demonstrated that circulating xenoreactive natural antibody levels did not return to pretransplantation levels. The production of xenoreactive natural antibodies from the recipient's splenocytes was inhibited completely. Histologic examination of xenografts showed the feature of acute vascular rejection. Immunohistochemical studies demonstrated infiltration of cardiac xenografts by large numbers of macrophages, small numbers of natural killer cells, and a few $T$ cells. The infiltrating macrophages also showed expression of interleukin-1 and tumor necrosis factor. Diffuse deposition of immunoglobulin G, C1Q, C3, and fibrin on xenograft vasculature was observed. Interleukin-2 expression was not found in rejected cardiac xenografts. Xenograft endothelial cells also showed evidence of activation (expression of cytokines interleukin-1 and tumor necrosis factor). Conclusions: This study demonstrates prolonged discordant cardiac xenograft survival and delayed xenograft rejection in a pig-to-baboon model. The delayed xenograft rejection is mediated by both humoral and cellular mechanisms. Pretransplantation total lymphoid irradiation combined with cyclosporine $A$ and methotrexate can inhibit xenoreactive natural antibody production but not elicited antipig antibody production and the xenoreactivity of macrophages. (J Thorac Cardiovasc Surg 1998;115:1342-9)
From the Cardiac Transplantation Research Laboratory, Division of Cardiothoracic Surgery, Department of Surgery, ${ }^{\text {a }}$ the Department of Pathology, ${ }^{\mathrm{C}}$ and the Department of Radiation Medicine, ${ }^{\mathrm{d}}$ Loma Linda University Medical Center, Loma Linda, Calif., and the Sandoz Center for Immunobiology, New England Deaconess Hospital, Harvard Medical School, Boston, Mass. $^{\mathrm{b}}$

Presented in part at the Fourth International Congress for Xenotransplantation, Sept. 7-11, 1997, Nantes, France.

Received for publication Dec. 5, 1997; accepted for publication Jan. 15, 1998.

Address for reprints: Steven R. Gundry, MD, Department of Surgery, Loma Linda University Medical Center, 11234 Anderson St., Loma Linda, CA 92354.

Copyright (c) 1998 by Mosby, Inc.

$0022-5223 / 98 \$ 5.00+0 \quad \mathbf{1 2} / \mathbf{1} / \mathbf{8 8 9 4 1}$
Clinical cardiac allotransplantation has been limUited by a critical shortage of donor organs. ${ }^{1}$ Cross-species transplantation has been proposed as an alternative to allograft transplantation. Unlike concordant xenografts (transplantation between closely related species), discordant xenografts (transplantation between widely disparate species) are usually hyperacutely rejected; the pathogenesis of hyperacute rejection is believed to be mediated by the binding of circulating xenoreactive natural antibodies to xenograft endothelium and activation of the classical complement pathway resulting in endothelial cell injury. ${ }^{2}$

To prevent hyperacute rejection, early investigations have focused on xenoreactive natural anti- 


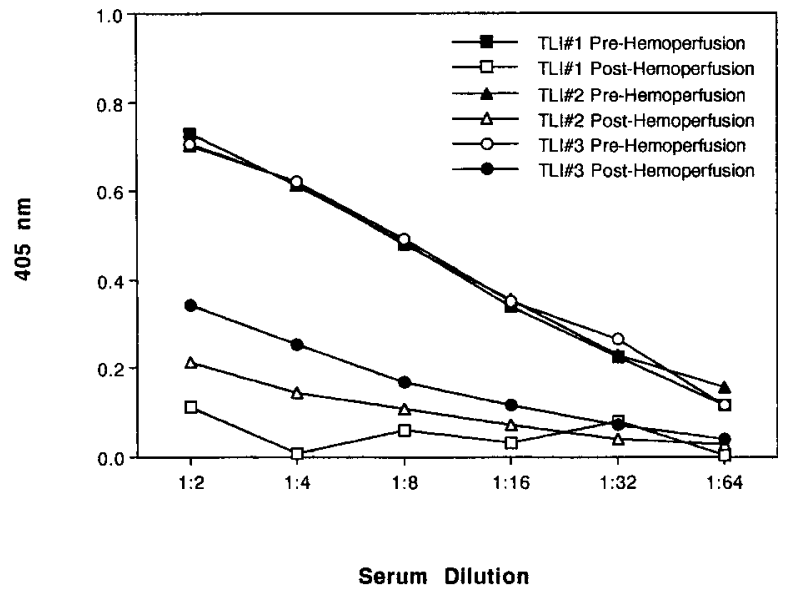

Fig. 1. Change of xenoreactive natural antibody levels in recipients before and after donor organ hemoperfusion.

bodies and complement depletion using plasma exchange, ${ }^{3}$ donor organ hemoperfusion, ${ }^{4}$ and inhibition of complement. ${ }^{5}$ Despite these measures, only limited xenograft survival has been achieved. Although hyperacute rejection of discordant xenografts has been overcome, the late phase of xenograft rejection, termed delayed xenograft rejection, has become the major barrier to the long-term xenograft survival. ${ }^{6}$ Cooper and associates ${ }^{4}$ have demonstrated severe acute cellular rejection in one heterotopically transplanted heart xenograft that survived more than 5 days. ${ }^{4}$ Blakeley, Hancock, and their associates ${ }^{6}$ have extensively evaluated the pathogenesis of delayed xenograft rejection in a guinea pig-to-rat cardiac xenograft model; and endothelial cell activation and macrophages appear important in the delayed xenograft rejection. In addition, Millan and coworkers ${ }^{7}$ have recently demonstrated evidence of porcine endothelial cell activation in response to human macrophages/monocytes in an in vitro study.

In a pig-to-baboon cardiac xenotransplant model, $\mathrm{we}^{8}$ have shown prolonged xenograft survival and delayed xenograft rejection. Immunologic analysis of blood samples also demonstrated increased levels of xenoreactive natural antibodies after transplantation, suggesting that these antibodies play an important role in delayed xenograft rejection. In the current study, we extended our investigation to examine the effectiveness of pretransplantation total lymphoid irradiation (TLI) combined with immunosuppression in inhibiting delayed xenograft rejection in a pig-to-baboon model of orthotopic cardiac xenotransplantation. We have also attempted to
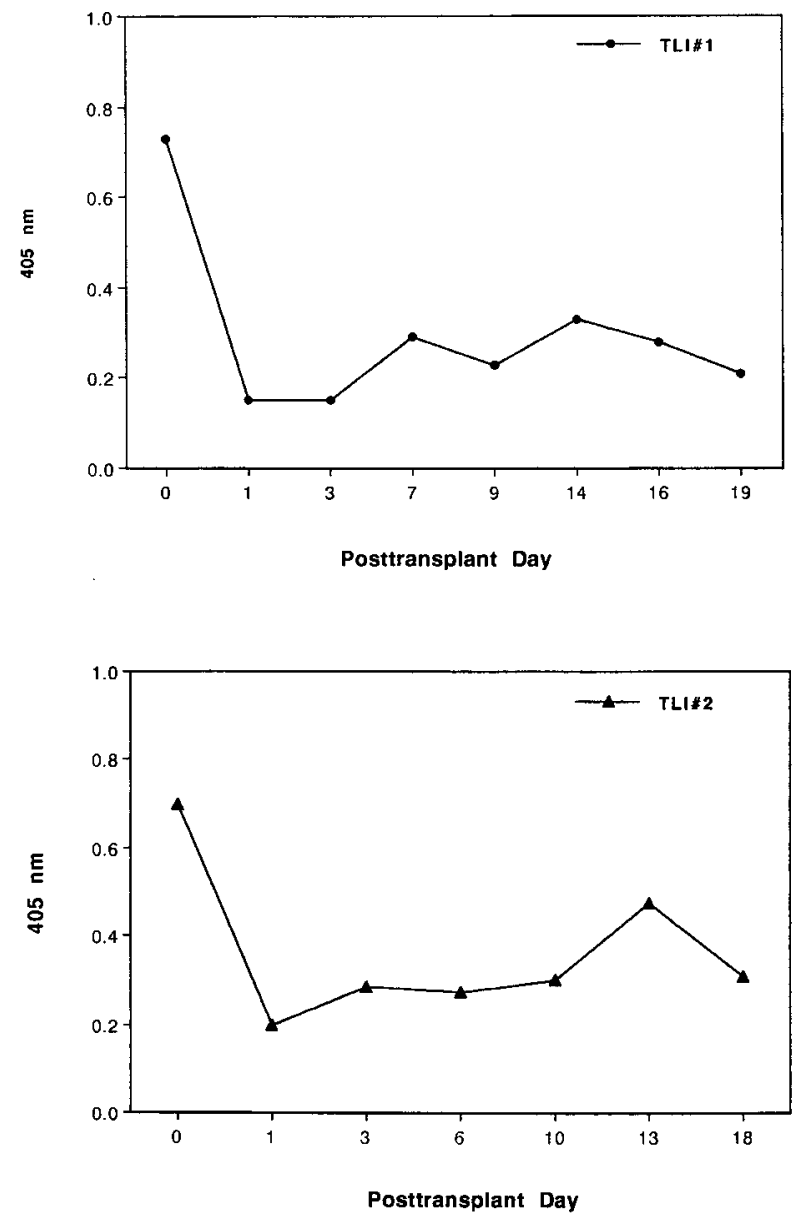

Fig. 2. Change of xenoreactive natural antibody levels in recipients before and after orthotopic pig cardiac xenotransplantation.

characterize the delayed xenograft rejection in the orthotopic cardiac xenograft model using immunohistochemical staining.

\section{Materials and methods}

Animals. Three juvenile baboons, 1 to 2 years of age and weighing 2.5 to $3.5 \mathrm{~kg}$, were used as recipients. Newborn piglets, weighing 3 to $4 \mathrm{~kg}$, were used as heart donors. Three pigs, weighing $10 \mathrm{~kg}$, were used as organ hemoperfusion donors (lung donors). All animals were maintained with humane care in compliance with the "Guide for the Care and Use of Laboratory Animals" prepared by the Institute of Laboratory Animal Resources and published by the National Institutes of Health (NIH Publication No. 86-23, revised 1985).

Immunosuppression. Recipients were treated with 80 cGy from a 60 Co source twice a week for 5 weeks (total 800 cGy) in the Department of Radiation Medicine, Loma Linda University Medical Center. One recipient received an additional $400 \mathrm{cGy}$ (100 cGy for 4 consecutive days) of 


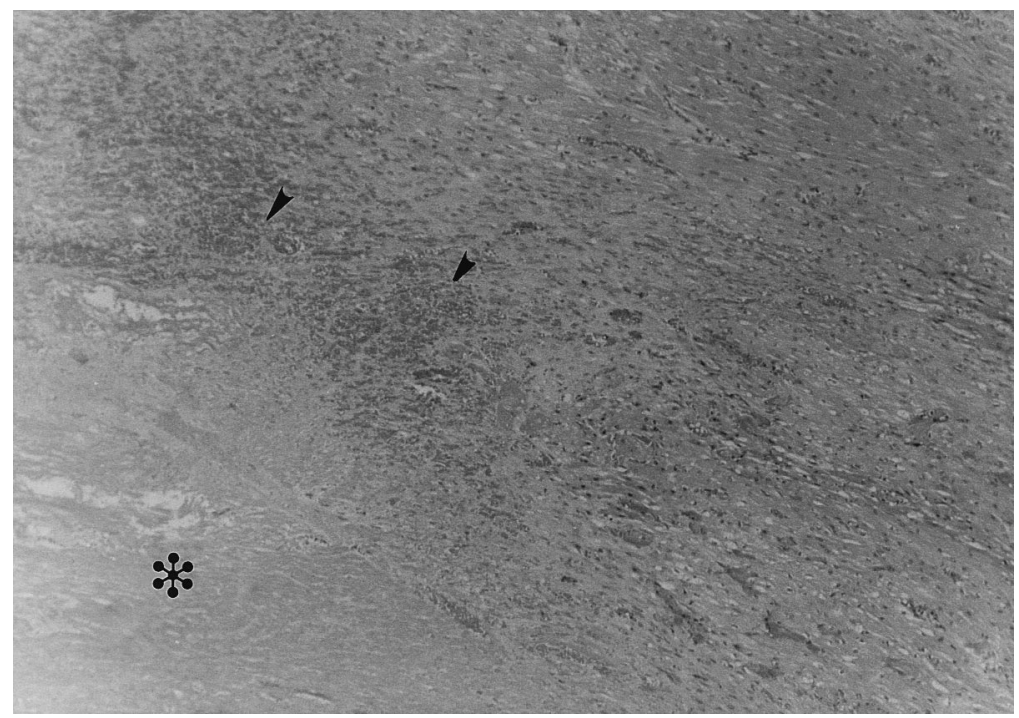

Fig. 3. Histology of xenograft from baboon TLI\#1 (hematoxylin and eosin staining) demonstrating acute infarction (asterisk) and interstitial hemorrhage (arrowheads).

Table I. Supernatant intracellular antibodies released from pokewood mitogen-stimulated baboon splenocytes

\begin{tabular}{lccc}
\hline Supernatant samples & $\begin{array}{c}I g M \\
(n g / m l)\end{array}$ & $\begin{array}{c}\text { IgG } \\
(n g / m l)\end{array}$ & $\begin{array}{c}\text { Anti- } \alpha G a l \\
\text { antibody* }\end{array}$ \\
\hline Pig & 0.0 & 0.0 & 0.092 \\
Normal baboon \#1 & 4390.0 & 955.6 & 0.955 \\
Normal baboon \#2 & 3327.5 & 322.2 & 0.870 \\
Normal baboon \#3 & 3923.3 & 63.3 & 1.006 \\
Normal baboon \#4 & 5219.2 & 271.1 & 0.831 \\
TLI baboon \#1 & 0.0 & 0.0 & 0.014 \\
TLI baboon \#2 & 0.0 & 291.0 & 0.110 \\
TLI baboon \#3 & 63 & 14 & 0.325 \\
\hline
\end{tabular}

*Outer diameter $=405 \mathrm{~nm}$.

splenic irradiation after completion of TLI. Pretransplantation immunosuppression consisted of intravenous methotrexate twice a week $(2 \mathrm{mg} / \mathrm{kg})$ for 4 weeks and intramuscular cyclosporine A (INN: ciclosporin), $15 \mathrm{mg} / \mathrm{kg}$ per day for 1 week. All recipients received perioperative antithymocyte globulin at $15 \mathrm{mg} / \mathrm{kg}$ per day from day 3 to 4 and methylprednisolone intravenously ( $125 \mathrm{mg} /$ day) for 3 days after orthotopic cardiac transplantation. Posttransplantation immunosuppression was maintained with intravenous methotrexate, $2 \mathrm{mg} / \mathrm{kg}$ twice a week, and cyclosporine A, $15 \mathrm{mg} / \mathrm{kg}$ per day intramuscularly. Recipients were treated with additional intravenous methylprednisolone (125 mg/day) when rejection occurred.

Depletion of xenoreactive natural antibodies and orthotopic cardiac transplantation. Both heart and lung donors were sedated with ketamine hydrochloride $(10 \mathrm{mg} /$ $\mathrm{kg}$ ), and sedation was maintained with inhalational halothane $(0.5 \%$ to $3 \%)$ and oxygen after endotracheal intubation. Donors were monitored by electrocardiogra- phy. Donor hearts were exposed through a median sternotomy and preserved with cold cardioplegic solution (Roe's solution, $50 \mathrm{ml} / \mathrm{kg}$ ), and donor lungs were preserved with $500 \mathrm{ml}$ cold Collins solution containing $500 \mu \mathrm{g}$ aprostadil (prostaglandin $\mathrm{E}_{1}$ ). Both the heart and lungs were stored in cold saline solution until donor organ hemoperfusion and cardiac transplantation.

Anesthesia in the recipients was induced and maintained with inhalational fluroxane (1\% to $3 \%)$ and oxygen. The recipients' hearts were exposed through a median sternotomy and removed after cardiopulmonary bypass had been established. Donor lungs were placed in the cardiopulmonary bypass line and the pulmonary artery was perfused for 60 minutes with the recipients' blood to remove xenoreactive natural antibodies before transplantation. Blood egressing from the pulmonary veins of the lungs was returned to the bypass circuit. Blood samples were collected before and after donor organ hemoperfusion for analysis of xenoreactive natural antibodies. Pigto-baboon orthotopic cardiac transplantation was performed according to techniques previously described. ${ }^{9}$ Packed baboon red blood cells were added to the cardiopulmonary bypass circuit before rewarming.

Posttransplantation monitoring. Pig cardiac xenografts were monitored daily by two-dimensional echocardiography. Blood samples were collected for analysis of xenoreactive natural antibodies. At the time of cessation of xenografts, myocardial tissue was collected for histologic and immunohistochemical analysis. Recipients' spleens were also harvested so that the production of xenoreactive antibodies could be studied.

Preparation of splenocytes. Baboon spleens were collected in cold $\left(4^{\circ} \mathrm{C}\right)$ RPMI-1640 medium (Gibco Laboratories, Grand Island, N.Y.). The spleens were minced, and a fine sterile steel mesh filter was used to remove the connective tissue capsule. The cells were washed three times with cold Hanks medium (Gibco) and then resus- 


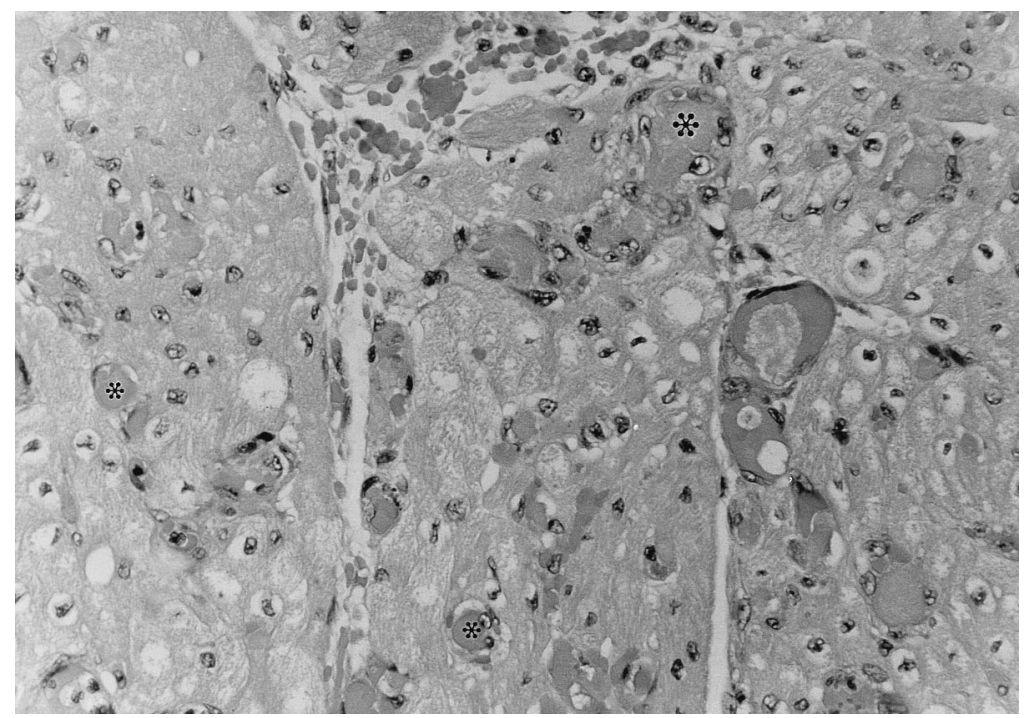

Fig. 4. Photomicrograph of xenograft from baboon TLI\#2 demonstrating microvascular thrombosis (some marked with asterisks).

pended in $0.83 \%$ buffered hypotonic TRIS-ammonium chloride at $4^{\circ} \mathrm{C}$ to lyse red blood cells. The splenocytes were rewashed three times with RPMI-1640 medium and their viability was examined by trypan blue exclusion to $90 \%$.

Pokeweed mitogen stimulation of splenocytes. Cryopreserved splenocytes were thawed and washed twice in RPMI-1640 medium. The cells were then resuspended in complete media (RPMI-1640, 20\% fetal bovine serum, glutamate $2 \mathrm{mmol} / \mathrm{L}, 200 \mathrm{IU}$ penicillin/100 $\mu \mathrm{g}$ streptomycin, pyruvate $1 \mathrm{mmol} / \mathrm{L}$, ITS (insulin, transferrin, and sodium selenite), and $50 \mu \mathrm{g} \beta$-mercaptoethanol) and adjusted to a concentration of $2 \times 10^{6}$ cells per milliliter. The cells were than placed in an incubator with humidified $5 \%$ carbon dioxide at $37^{\circ} \mathrm{C}$ and rested overnight. The cells were harvested and resuspended at $2 \times 10^{6}$ cells per milliliter in complete media containing pokeweed mitogen $500 \mu \mathrm{g} / \mathrm{ml}$ (Sigma, St Louis, Mo.) and then incubated for 7 days. At the end of incubation, cells were harvested, centrifuged, and the supernatant was collected. Aliquots were frozen and stored at $-70^{\circ} \mathrm{C}$.

Supernatant immunoglobulin quantification. Immunoglobulin levels in cell culture supernatants were determined by an enzyme-linked immunosorbent assay (ELISA). Mouse monoclonal antibodies to either baboon immunoglobulin M or G (IgM or IgG, PharMingen, San Diego, Calif.) were adsorbed onto the surface of a microtiter plate at $4^{\circ} \mathrm{C}$ overnight. The plates were washed three times with triethanolamine-buffered saline solution (TBS), and nonspecific binding sites were blocked with SuperBlock Blocking Buffer in TBS and then air dried. The plates were then washed three times with TBS-Tween followed by the addition of standards and cell culture supernatants to the appropriate wells. After 2 hours' incubation, the plates were washed three times with TBS-Tween solution and the appropriate secondary antibodies were added (alkaline phosphatase-labeled mono- clonal mouse antihuman IgM, PharMingen, San Diego, Calif., and IgG, Fisher, Pittsburgh, Pa.). The plates were incubated at room temperature for 2 hours. After a final wash with TBS-Tween solution, the substrate was added. The absorbance of each well was measured at $405 \mathrm{~nm}$ within 1 hour.

Measurement of xenoreactive natural antibodies in the serum and supernatant. The supernatant and serum levels of xenoreactive natural antibodies were measured by an ELISA using the method described by Kujundzic and associates. $^{10}$ Gal antigens- $\alpha \operatorname{Gal}(1-3) \beta \mathrm{Gal}(1-4) \mathrm{GlcNac}-$ BSA (V-LABS, Inc., Covington, La.) were adsorbed onto the surface of a microtiter plate at $4^{\circ} \mathrm{C}$ for 17 hours. The plates were washed three times with TBS, and nonspecific binding sites were blocked with SuperBlock Blocking Buffer in TBS. Immediately before the assay, the plates were washed three times with TBS-Tween solution. Cell culture supernatants from pokeweed mitogen-stimulated splenocytes and serum samples were added to the wells and incubated for 2 hours at room temperature. The plates were washed four times with TBS-Tween solution followed by addition of the secondary antibody (alkaline phosphatase-labeled antihuman IgM and IgG, Fisher, Pittsburgh, Pa.). After 2 hours of incubation at room temperature, the plates were rewashed four times with TBS-Tween solution. Substrate was added to the wells and after 1 hour the absorbance of each well was measured at $405 \mathrm{~nm}$.

Histology and immunohistology. Biopsy specimens of the cardiac xenografts were collected and fixed in $10 \%$ neutral-buffered formalin. Standard paraffin sections were prepared and stained with routine hematoxylin and eosin stain and examined microscopically. Small pieces of cardiac xenografts were snap-frozen in ornithine carbamyltransferase (OCT) medium and then stored at $-70^{\circ} \mathrm{C}$ until immunohistologic analysis. After cryostat sections were fixed with paraformaldehyde-lysineperiodate, tissue sec- 


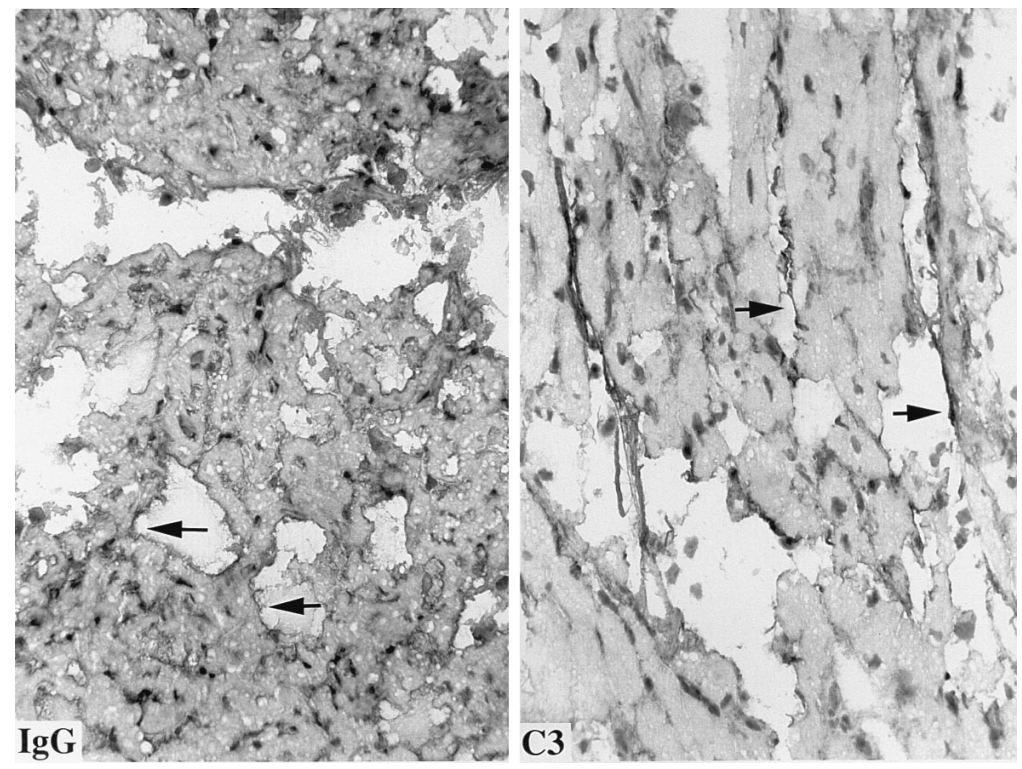

Fig. 5. Immunopathologic studies of rejected pig hearts from baboons showed diffuse endothelial membrane staining for IgG (left, arrows) and complement C3 (right, arrows).

tions were than stained with antibodies to $\operatorname{IgM}, \operatorname{IgG}, \mathrm{C} 1 \mathrm{q}$, $\mathrm{C} 3$, and fibrin to determine humoral rejection; monoclonal antibodies to macrophages, T cells, B cells, to identify the types of infiltrating baboon leukocytes; and an antibody to the cytokine IL-1 and IL-2, tumor necrosis factor (TNF- $\alpha$ ), as previously described. ${ }^{6}$

\section{Results}

Xenograft survival and natural antibody titers. Two recipients (TLI\#1 and TLI\#2) fully recovered from orthotopic cardiac transplantation without technical failure, and all xenografts functioned well without any evidence of hyperacute rejection. One recipient (TLI\#3) died 3 hours after transplantation because of multiple arrhythmias and hemodynamic instability but lacked evidence of immediate hyperacute rejection. Pig cardiac xenograft survival times were 18 and 19 days before death.

Serum levels of xenoreactive natural antibodies were reduced significantly after pretransplantation donor organ hemoperfusion without returning to pretransplantation levels (Fig. 1). Very low levels of xenoreactive natural antibodies in serum samples obtained after transplantation were observed; this low level was maintained until the recipients died (Fig. 2).

Xenoreactive natural antibody production and release from baboon splenocytes. Table I summarizes production and release of intracellular anti- bodies from baboon splenocytes. As positive controls, normal baboon splenocytes released very high levels of IgM and IgG antibodies. ELISA demonstrated that these intracellular antibodies directly recognized and bound to pig xenoantigens at very high levels. In contrast, the recipients' splenocytes failed to produce and release high levels of antibodies including xenoreactive natural antibodies. Only one recipient showed $\mathrm{IgG}$ antibody formation. The binding levels of xenoreactive natural antibodies to pig xenoantigens remained very low.

Immunopathology of xenografts. At the time of cessation of cardiac xenografts, gross appearance of xenografts included swollen, thickened cardiac walls and hemorrhage. Histologic study revealed evidence of acute vascular rejection, which included interstitial edema and hemorrhage, microvascular thrombosis, and acute infarction (Figs. 3 and 4).

Immunohistochemical staining of rejected xenografts demonstrated deposition of baboon $\operatorname{IgM}, \mathrm{IgG}$, C1q, C3, and fibrin on the surface of xenograft endothelial cells, suggesting humoral rejection (Fig. $5)$. The infiltrate of cardiac xenografts consisted of large numbers of macrophages and smaller numbers of natural killer (NK) cells (10\% to $20 \%)$. Very few $\mathrm{T}$ cells were seen in xenografts (Fig. 6). The infiltrating macrophages showed expression of IL-1 $\beta$ and TNF- $\alpha$, and the expression of IL- $1 \beta$ and TNF- $\alpha$ 


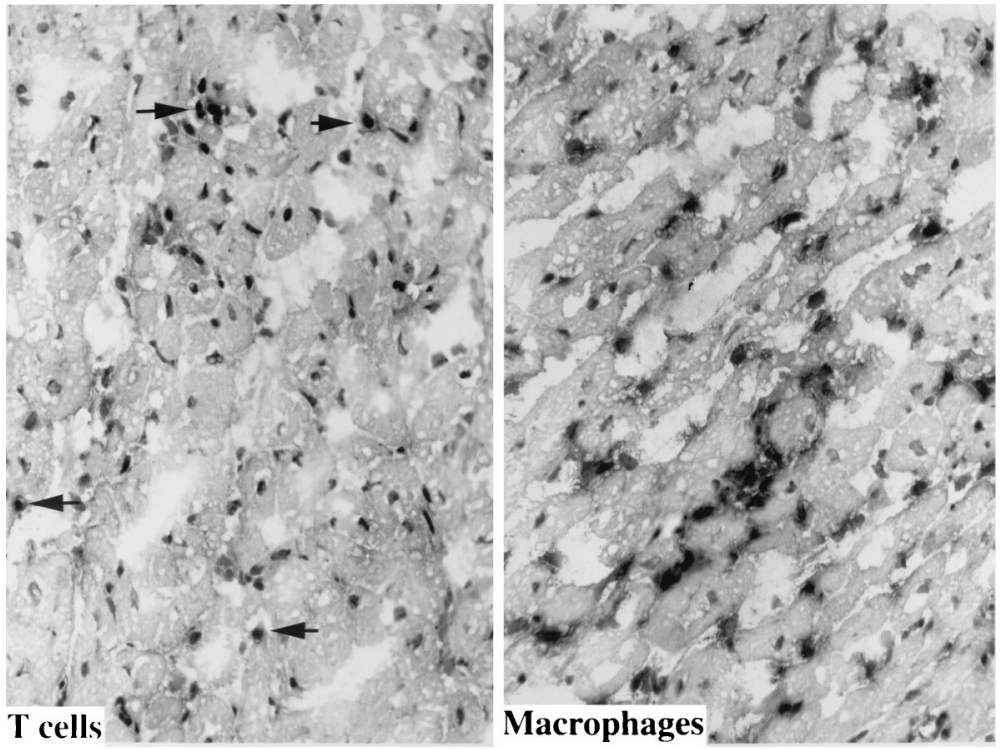

Fig. 6. Immunopathologic studies of rejected pig hearts from baboons showed positive staining for few T-cell infiltrates (left, arrows) and large numbers of macrophages (right).

on xenograft endothelial cells and myocardial areas was observed in close relationship to macrophage infiltration (Fig. 7). The expression of IL-2 on infiltrating $\mathrm{T}$ cells and xenografts was not identified (data not shown).

\section{Discussion}

Hyperacute rejection mediated by the recipient's circulating xenoreactive natural antibodies and complement has been considered as the first major barrier to successful discordant cardiac xenografting. Previous studies have shown that depletion of xenoreactive natural antibodies and complement can prevent hyperacute rejection and results in limited prolongation of xenograft survival. ${ }^{3-5,8}$ In this study, we were able not only to deplete baboon circulating xenoreactive natural antibodies but also inhibit their production using pretransplantation TLI and immunosuppression resulting in 18 and 19 days' survival of orthotopic xenografts. TLI has been used as immunosuppressive therapy or tolerance induction therapy in both allograft $\mathrm{t}^{11,12}$ and concordant xenograft transplantation ${ }^{13,14}$ and has been shown to be effective in inhibiting antidonor antibody production and cell-mediated responses.

Increasing evidence suggests that discordant xenograft rejection (after overcoming hyperacute rejection) is associated with increased synthesis of xenoreactive natural antibodies. A previous study by us has shown that posttransplantation production of xenoreactive natural antibodies corresponded with xenograft rejection in a pig-to-baboon cardiac xenograft model receiving immunosuppressive therapy of cyclosporine $\mathrm{A}$ and 15 -deoxyspergualin. ${ }^{15} \mathrm{In}$ a pigto-human liver perfusion study, Cotterell and associates ${ }^{16}$ demonstrated an increase in concentration of xenoreactive natural antibodies that directly recognized pig xenoantigens. The present study provides important information regarding the immunosuppressive effectiveness of TLI combined with immunosuppression of cyclosporine A and methotrexate on the production of xenoreactive natural antibodies in a discordant xenograft model. We have demonstrated low levels of circulating xenoreactive natural antibodies in all recipients after xenotransplantation and the inhibition of xenoreactive natural antibody production from the recipient's splenocytes. We assume that this treatment protocol directly suppresses B cell activity, particularly on B cells that produce xenoreactive natural antibodies.

In contrast, this combined therapy failed to block the production of elicited antidonor antibodies that were detected by immunohistochemical staining showing the deposition of antibody and complement on xenografts. We speculate that the mechanism of elicited antidonor antibody production is a $\mathrm{T}$ cellindependent $\mathrm{B}$ cell response, since we did not demonstrate the presence of $\mathrm{T}$ cells in the xenografts and expression of IL-2.

It has been widely believed that the recipient's 


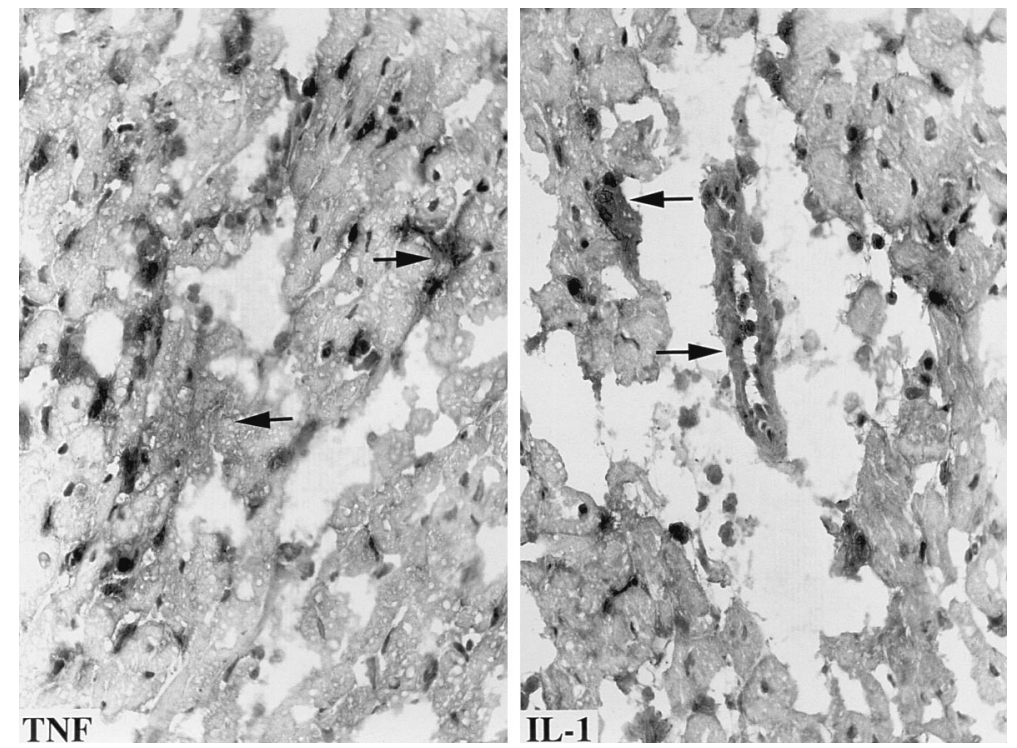

Fig. 7. Immunopathologic studies of rejected pig hearts from baboons showed expression of TNF- $\alpha$ (left) and IL-1 $\beta$ (right) by infiltrating macrophages. TNF- $\alpha$ staining includes the area surrounding macrophages, as well as adjacent endothelial cells and focal myocardial areas. IL- $1 \beta$ was observed in close relationship to macrophages, plus locally on the surfaces of endothelial cells (arrows).

immune system will recognize and respond to xenografts once hyperacute rejection is overcome, resulting in so-called delayed xenograft rejection. The present study demonstrates the pathogenic mechanisms of delayed xenograft rejection in an orthotopic pig-to-baboon cardiac xenograft model. This study has found evidence of both humoral and cellular rejection mechanisms in xenografts undergoing delayed xenograft rejection, including deposition of antibody and complement and cellular infiltration. Unlike allografts or concordant xenografts, the majority of infiltrating lymphoid cells were macrophages, $10 \%$ to $20 \%$ NK cells, but very small numbers of $\mathrm{T}$ cells, suggesting that macrophages/NK cells play an important role in delayed xenograft rejection. Blakeley, Hancock, and their associates ${ }^{6}$ showed progressive infiltration of macrophages in a guinea pig-to-rat cardiac xenograft model that was treated with cobra venom factor. However, this guinea pig-to-rat model did not demonstrate humoral rejection resulting from the complement depletion by cobra venom factor. ${ }^{6}$ Candinas and coworkers ${ }^{17}$ demonstrated that macrophages/NK cellmediated delayed xenograft rejection is not altered by the presence or absence of $\mathrm{T}$ cells. In an in vitro study, Vallee and colleagues ${ }^{18}$ have shown decreased lymphocyte proliferation in response to pig endothelial cells after depletion of macrophaged monocytes. In our study, although a small number of $\mathrm{T}$ cells were present in xenografts, there was a lack of IL-2 expression on xenografts. This evidence suggests that $\mathrm{T}$ cells do not play an important role in the early phase of delayed xenograft rejection in discordant xenografts.

In this study, pig xenografts undergoing delayed rejection demonstrated evidence of xenograft vascular endothelial activation and activated macrophages/NK cells. The expression of IL-1, TNF- $\alpha$, and E-selectin was observed and could be associated with macrophage xenoreactivity. A previous study showed type II endothelial cell activation in delayed xenograft rejection, including expression of P-selectin, E-selectin, and von Willebrand factor. The expression of selectin is associated with production of interferon, TNF- $\alpha$, IL-1, and other cytokines. ${ }^{6}$ Furthermore, in a recent in vitro study, Millan and coworkers $^{7}$ demonstrated that direct contact of monocytes/macrophages and porcine endothelial cells can induce E-selectin expression on porcine endothelial cells, and human IL-1 $\alpha$ induces expression of E-selectin on endothelial cells. These findings suggest that activation of macrophages/NK cells and xenograft vascular endothelial cells play an important role in delayed xenograft rejection of discordant xenotransplantation.

As an alternative to clinical allotransplantation, 
the application of discordant cardiac xenografts to human beings is still limited by delayed xenograft rejection. However, consistent 21/2 weeks' orthotopic discordant cardiac xenograft survival can be achieved using TLI and novel but conventional immunosuppression in this pig-to-baboon model. This study demonstrates that induced antipig (rather than naturally occurring) antibody production and macrophages/NK cells are responsible for the delayed xenograft rejection. This information further strengthens our hypothesis that pig-to-human heart xenotransplantation may eventually be feasible when activation of xenograft endothelial cells and delayed xenograft rejection can be overcome.

\section{REFERENCES}

1. McManus RP, O'Hair DP, Beitzinger JM, et al. Patients who die awaiting heart transplantation. J Heart Lung Transplant 1993;12:159-72.

2. Platt JL, Vercellotti GM, Dalmasso AP, Matas AJ, Bolman RM, Najarian JS, et al. Transplantation of discordant xenografts: a review of progress. Immunol Today 1990;11:450-6.

3. Reding R, Davies H, White D, et al. Effect of plasma exchange on guinea pig-to-rat heart xenografts. Transplant Proc 1989;21:534.

4. Cooper DKC, Human PA, Lexer G, et al. Effects of cyclosporine and antibody adsorption on pig cardiac xenograft survival in the baboon. J Heart Transplant 1988;7: 238-46.

5. Leventhal JR, Dalmasso AP, Cromwell JW, et al. Prolongation of cardiac xenograft survival by depletion of complement. Transplantation 1993;55:857-66.

6. Blakely ML, Van Der Werf WL, Berndt MC, et al. Activation of intragraft endothelial and mononuclear cells during discordant xenograft rejection. Transplantation 1994;58:105966.

7. Millan MT, Geczy C, Stuhlmeier KM, Goodman DJ, Ferran C, Bach FH. Human monocytes activate porcine endothelial cells, resulting in increased E-selectin, interleukin-8, monocyte chemotactic protein-1, and plasmino- gen activator inhibitor-type-1 expression. Transplantation 1997;63:421-9.

8. Fukushima N, Gundry SR, Matsumiya G, Bouchart F, Zuppan C, Bailey LL. Histological findings in heart grafts after orthotopic pig to baboon cardiac transplantation. Transplant Proc 1996;28:788-90.

9. Bailey LL, Jang J, Johnson W, Jolley WB. Orthotopic cardiac xenografting in the newborn goat. J Thorac Cardiovasc Surg 1985;89:242-9.

10. Kujundzic M, Koren E, Neethling FA, et al. Variability of anti- $\alpha \mathrm{Gal}$ antibodies in human serum and their relation to serum cytotoxicity against pig cells. Xenotransplantation $1994 ; 1: 58$

11. Gottlieb M, Strober S, Hoppe RT, Grumet FC, Kaplan HS. Engraftment of allogeneic bone marrow without graft-versushost disease in mongrel dogs using total lymphoid irradiation. Transplantation 1980;29:487-91.

12. Myburgh JA, Smit JA, Hill RR, Browde S. Transplantation tolerance in primates following total lymphoid irradiation and allogeneic bone marrow injection. II. Renal allografts. Transplantation 1980;29:405-8.

13. Roslin MS, Tranbaugh RE, Panza A, et al. One-year monkey heart xenograft survival in cyclosporine-treated baboons. Transplantation 1992;54:949-55.

14. Myburgh JA, Smit JA, Stark JH. Transplantation tolerance following total lymphoid irradiation in baboon-to-vervet monkey kidney xenotransplantation. Transplant Proc 1994; 26:1081.

15. Fukushima N, Bouchart F, Gundry SR, et al. The role of anti-pig antibody in pig-to-baboon cardiac xenotransplant rejection. Transplantation 1994;57:923-8.

16. Cotterell AH, Collins BH, Parker W, Harland RC, Platt JL. The humoral immune response in humans following cross-perfusion of porcine organs. Transplantation 1995; 60:861-8.

17. Candinas D, Koyamada N, Miyatake T, et al. T cell-independence of macrophage and NK cell infiltration, cytokine production and endothelial activation during delayed xenograft rejection. Transplantation 1996;62:1920-8.

18. Vallee I, Watier H, Thibault G, et al. Evidence of noninvolvement of swine MHC class II in the in vitro proliferative response of human lymphocytes to porcine endothelial cells. Transplantation 1995;59:897-901. 